BULLETIN Bulletin hispanique

HISPANIQUE Université Michel de Montaigne Bordeaux

114-1 | 2012

Varia

\title{
Rafael Bonilla Cerezo (ed.), Novelas cortas del siglo XVII
}

Cátedra, Madrid, 2010

Fernando Rodríguez Mansilla

\section{CpenEdition}

\section{Journals}

Edición electrónica

URL: http://journals.openedition.org/bulletinhispanique/1950

DOI: 10.4000/bulletinhispanique.1950

ISSN: 1775-3821

\section{Editor}

Presses universitaires de Bordeaux

\section{Edición impresa}

Fecha de publicación: 1 junio 2012

Paginación: 472-481

ISBN: 978-2-86781-812-7

ISSN: 0007-4640

\section{Referencia electrónica}

Fernando Rodríguez Mansilla, «Rafael Bonilla Cerezo (ed.), Novelas cortas del siglo XVII », Bulletin hispanique [En línea], 114-1 | 2012, Publicado el 27 mayo 2013, consultado el 22 septiembre 2020 URL : http://journals.openedition.org/bulletinhispanique/1950 ; DOI : https://doi.org/10.4000/ bulletinhispanique.1950

Este documento fue generado automáticamente el 22 septiembre 2020

Tous droits réservés 


\section{Rafael Bonilla Cerezo (ed.), Novelas cortas del siglo XVII}

Cátedra, Madrid, 2010

Fernando Rodríguez Mansilla

\section{REFERENCIA}

Rafael Bonilla Cerezo (ed.), Novelas cortas del siglo XVII. - Madrid, Cátedra, 2010, 376 pp.

1 El reciente volumen de Novelas cortas del siglo XVII editado por Rafael Bonilla Cerezo supone una contribución significativa para el estudio de este género narrativo, vigoroso durante el Barroco, pero abordado con un interés menor por la crítica aurisecular del siglo XX, más inclinada al teatro (que sigue siendo el gran tema de las conferencias dedicadas al Siglo de Oro español), a la poesía o al legado cervantino. El género de la novela corta, con la excepción de las Novelas ejemplares, gozó de una mediocre fortuna editorial en el siglo recientemente pasado, caracterizada tal vez por iniciativas aisladas. La primera de estas fue el ambicioso proyecto de Emilio Cotarelo, quien publicó entre 1906 y 1909 doce volúmenes de su Colección selecta de antiguas novelas españolas. Más adelante, en la década del cincuenta, la editorial barcelonesa Selecciones Bibliófilas hizo lo suyo para difundir algunos exponentes de novela corta barroca, tal es el caso de las Novelas amorosas de José Camerino.

2 Tendríamos que llegar hasta la década del ochenta para encontrar un proyecto similar al que nos propone ahora Bonilla Cerezo. Estas Novelas cortas del siglo XVII cuentan con el precedente de las Novelas amorosas de diversos ingenios (1986), antología preparada por Evangelina Rodríguez Cuadros, fruto de un interés surgido de su estudio dedicado a José Camerino y Andrés de Prado: Novela corta marginada del siglo XVII español (1979). Con la antología de 1986, la investigadora intentaba, de paso, consolidar el término que había acuñado y daba título a su monografía, con límites y alcances muy específicos, en particular en lo que se refiere a la función ideológica del discurso novelesco, anclado en el marco de la cultura dirigida que caracterizaba, según lo esbozó José Antonio 
Maravall, al periodo barroco. Aunque después se sumió en nuevos derroteros críticos, Rodríguez Cuadros se dio tiempo para dar a luz otra colección de novela corta, también con propósito específico, aunque distinto (la singularidad de la escritura femenina): Entre la rueca y la pluma. Novelas de mujeres en el Barroco (1999), que incluía piezas de María de Zayas, Leonor de Meneses y Mariana de Carvajal. Tras esta semblanza de la tradición editorial, no del todo breve, que precede a las Novelas cortas del siglo XVII y ayuda a resaltar su mérito, comentaremos, a continuación, ideas y aciertos interpretativos de Bonilla Cerezo. Adicionalmente, elaboraremos algunas notas en torno a ciertos pasajes, las cuales pueden cooperar a la mejor comprensión de los textos incluidos en la presente antología.

3 Sumado al hecho de que el corpus genérico es amplio, es un lugar común (que no por eso falaz) que la heterogeneidad impera dentro del género de la novela corta. Por ende, acierta Bonilla en establecer al menos dos formas básicas de novelar a partir de la estructura narrativa que pueden asumir los textos. La primera sería la cervantina, que propugna una suerte de llaneza y vocación por el relato de corrido; esta integra y devora múltiples modalidades narrativas heredadas del XVI. Luego, a contrapelo de la vía de Cervantes, encontramos la que suele identificarse con Lope de Vega y sus «intercolunios» o digresiones eruditas que son marca de calidad de las Novelas a Marcia Leonarda. Dicha inclinación por la parafernalia verbal, al estar en contacto con la moda gongorina produciría, gracias a las diligentes plumas de ciertos autores después de 1620 , lo que Bonilla viene a calificar de «novela culta», o sea la novela corta impregnada del modelo lingüístico propuesto por Góngora. Indudablemente, la idea es muy rica y abre un panorama nuevo para leer textos cuya complejidad estilística así como sus referentes temáticos produjeron la incomprensión y el rechazo de la crítica. Ceñidos al paradigma cervantino, los investigadores despreciaron por lo general todos los ensayos que se alejaban de los parámetros establecidos por el alcalaíno (a las novelas de Lope las salvó su genialidad demostrada en el drama), tal como se hizo con los epígonos picarescos que tomaron distancia (por diversos motivos) de la pareja editorial que configuraron el Lazarillo de Tormes y el Guzmán de Alfarache en los primeros años del XVII.

4 En su somero estado de la cuestión, Bonilla acentúa la tendencia crítica imperante en la actualidad, de estudiar la novela corta como una muestra más de la cultura barroca, o sea un proyecto dirigido, con claro afán propagandístico, hacia un público, cuya subjetividad se empieza a dar forma y cuyas expectativas de reconocimiento social se ven saciadas en los textos ${ }^{1}$. Esta perspectiva sociológica es la que también comparte, en buena medida, Reyes Coll-Tellechea, para quien la novela «cortesana» es un producto dirigido a una élite social, la aristocracia castellana que se ve seducida por un discurso promonárquico y señorial ${ }^{2}$. El ensayo introductorio ofrecido por el editor da por sentados estos enfoques y se propone una exégesis más bien de índole formal. Consciente de la supremacía del género lírico en el Siglo de Oro, así como echando mano de su profundo conocimiento de la poesía culterana, el editor postula la impronta gongorina como fil rouge de análisis para la novela corta, proponiendo, como ya se mencionó, el rótulo de «novela culta» para las ficciones que establecen vasos comunicantes con el estilo propugnado por el cordobés.

5 De tal forma, la impronta culterana se pone a manifiesto en el plano temático en la medida en la que se transfiere la sofisticación y ambiente bucólico de los poemas mayores gongorinos, según lo reflejan algunas de las novelas editadas. Nos hallamos, 
como sostiene el editor, frente a una atmósfera altamente estetizante, ya que el estilo culto «está en el aire» durante el siglo XVII y se filtra en la prosa narrativa de varios modos, cada uno de los cuales se ejemplificará con la correspondiente novela dentro de la antología: la imposición de la dificultad conceptista como estilo, en Las dos hermanas; la incorporación de fragmentos de la Fábula de Polifemo y Galatea en novelas como La ingratitud hasta la muerte y La prodigiosa; la imitación en el plano formal y semántico de Las Soledades se halla presente en Del celoso desengañado; la crítica, en registro cómico, del estilo gongorino se ofrece en El culto graduado; finalmente, el barroquismo, entendido como estilo recargado, moroso, tanto en el plano de la sintaxis como en el léxico, que se impone entre 1640 y 1663, se atestigua en El monstruo de Manzanares. En suma, según lo indica Bonilla, este recorrido nos deja la impresión de «un triunfo culto, pues, que no corresponde al capricho de un solo autor ni a una moda arbitraria, seguida por frívolas razones» (p. 19).

6 Ahora bien, si tal es el eje en torno al cual gira la organización de los textos se percibe claramente que, como cualquier antología, las Novelas cortas del siglo XVII es una muestra parcial que no agota las perspectivas en torno al fenómeno literario abordado. Bonilla esboza el panorama crítico en torno al género y apunta, acertadamente, al silencio general que esta modalidad específica, la «novela culta», ha sufrido, como si Góngora no fuera digno de tan discreto homenaje o como si los entendidos percibieran la lírica y la narrativa como estancos separados de una forma tan rígida como inexistente en la época áurea. Más allá, en torno a la impronta de la comedia, el editor afirma que, en efecto, varios estudios han demostrado cómo la novela se «teatraliza» ${ }^{3}$. Pero el estudio de Marco Morínigo, citado muy de pasada como bibliografía adicional a este respecto, va por otros cauces: el concepto de «novela» que asume el crítico paraguayo es sumamente laxo en su trabajo, por lo cual incluye bajo esta categoría textos narrativos de muy diversa extensión, temática y estilo. Si algo habría que rescatar de la propuesta de Morínigo es su intento de explicar la marginalidad de la narrativa, con la excepción de Cervantes, frente al teatro durante el Barroco ${ }^{4}$. Actualmente, en aras de seguir ahondando en el género estudiado, la cuestión más bien sería esta: ¿cómo comprender esta interacción entre el discurso novelesco, la modalidad dramática y el debate en torno a los modelos de lengua literaria que se estaba llevando a cabo por aquellos años? ¿cuál es su verdadero impacto? En este sentido, Bonilla está abriendo una cala, la de la influencia del estilo y contenido gongorizante en la novela corta, alrededor de la cual seguiremos probablemente discutiendo en los años venideros.

7 La antología se abre con el texto de Las dos hermanas de Francisco Lugo y Dávila: se trata de una novela de breve extensión, con trama cerrada, casi como un exemplum, considerando la cita de Ausonio que abre y cierra el texto. El narrador pone de manifiesto la consciencia de manejar un estilo, adoptando una lengua de base conceptista con artificio moderado: el comentario en torno a un estilo genérico «conciso, mas no querría afectado» (p. 161), abre un puente desde 1622, cuando esta novela se publica dentro de la colección Teatro popular, hasta la novela El monstruo de Manzanares (contenida en La mojiganga del gusto, en 1643), la cual incluye frases de un barroquismo que puede transmitir inclusive un humor involuntario. Entre una novela y otra (un lapso de veinte años) ha pasado mucha agua debajo del puente de las tendencias literarias: la polémica y el triunfo póstumo de Góngora, el fallecimiento de Lope e inclusive la desaparición, sucesiva, de los dos narradores de mayor vigor luego de Cervantes: Alonso Jerónimo de Salas Barbadillo (muerto en 1635, pero con un 
descenso notable de su producción después de 1625) y Alonso de Castillo Solórzano (muy prolífico desde 1625 hasta su muerte, alrededor de 1642), escritores ceñidos a un modelo estilístico «llano», como deudores de Cervantes y Lope, en ese sentido, y de lectura amena y sencilla, si se les compara con aquellos otros narradores de cálamo algo más afectado y estridente.

En Las dos hermanas es digno de resaltar, a propósito de la confluencia de géneros que estimula la narrativa breve, la inclusión de poemas, los cuales revelan la calidad espectacular de los hechos y el entorno festivo que rodea a la vida en la corte madrileña. Nos hallamos frente a una atmósfera de burlas, confusiones y lances amorosos comunes también a la comedia urbana, cuyo auge se da precisamente en el reinado de Felipe IV $\mathrm{V}^{5}$. Se trata, en última instancia, de una materia compartida por Salas Barbadillo, cronista de la vida diurna y nocturna de Madrid, y por las piezas narrativas de Castillo Solórzano ambientadas en la metrópoli, como Las harpías en Madrid (1631), evocada justamente por Bonilla al comentar Las dos hermanas, y sobre todo Teresa de Manzanares (1632), cuya protagonista es la pícara capitalina por excelencia. La novela de Lugo y Dávila posee un sesgo costumbrista, con afán moralizante, cercano al tono más característico de Salas Barbadillo, considerando que este sigue en activo en los años de publicación de la obra. Se representa un Madrid espacio de aventuras galantes y terreno fértil para la burla aleccionadora, entretenimiento casi exclusivo de los grupos privilegiados, cuya estética y deontología se han labrado durante el reinado previo ${ }^{6}$. Por esto, en tal mundo narrativo lleno de enredos y confusiones de identidad propios del teatro, no resulta del todo oportuno hacer referencia, en la nota a pie de página, a la famosa escena nocturna del cofre con joyas cuando escapa de casa la heroína de la pieza lopesca Las fortunas de Diana, equiparándola con la de Lamia que usurpa la identidad de Delia en Las dos hermanas (p. 177). En la novela de Lope, Diana se encuentra en una situación completamente distinta, esperando la llegada de su novio para escapar con él, además de que la composición de ambos textos se da prácticamente en paralelo (Las fortunas de Diana es de 1621 y al año siguiente se publica el Teatro popular de Lugo). El recurso al ceceo que apunta Bonilla también podría inspirarse, visto así, en la escena de don Juan recibiendo el papel destinado a Mota en la segunda jornada de El burlador de Sevilla, cuya composición se suele situar por esos mismos años, alrededor de 1620 .

La segunda novela, La ingratitud hasta la muerte de José Camerino, es una muestra ejemplar de la introducción de fábulas, y de los recursos estilísticos del género bucólico en especial, en la prosa barroca. El impacto del modelo de la fábula mitológica, de largo aliento en la poesía burlesca ${ }^{7}$, llega hasta al propio Lope de Vega, quien en La desdicha por la honra escribiría teniendo en mente el género de la fábula mitológica ${ }^{8}$. Bonilla acierta en observar la construcción narrativa en cuadros o grandes escenas, como pinturas en rotación: «Toda la novela gira alrededor de tres pruebas y tres "cuadros" que pueden definirse como lienzos poéticos o tableaux» (p. 55). Nos hallamos frente a una composición eminentemente barroca, cual pequeño tour de force estilístico. Bonilla Cerezo apunta, con precisión y buen ojo lector, todos los paralelismos y deudas adquiridas con los versos de Góngora. En el terreno de la anotación, nos provoca simplemente sugerir un curioso parecido con El Abencerraje en la escena en la cual Floristo, tras derrotar a Ormindo, entrega la guirnalda de su victoria a la dueña de su corazón: «Vencí en el bosque a tus enemigos y de haberme vencido te corono» afirma el galán triunfador (p. 191). En la muy conocida novela morisca, Abindarráez, arrobado de amor, afirma que «hice una hermosa guirnalda y poniéndola sobre mi cabeza, me volví a ella, coronado y vencido. Ella puso los ojos en mí, a mi parescer más dulcemente que 
solía, y quitándomela, la puso sobre su cabeza» (p. 118) $)^{9}$. Las diferencias saltan a la vista: en La ingratitud hasta la muerte, Floristo entrega el premio que otros le han dado, en un ambiente de tintes caballerescos, como prenda de amor a la dama, quien se ofuscará; en El Abencerraje, la atmósfera bucólica, mucho más sofisticada, empapa a la pareja y la devolución de la corona implica una correspondencia de sentimientos. Sin embargo, cual desdichado Abencerraje, Floristo es un sentimental al que su amada Clérida fulmina con su frialdad. Su reacción se asemeja nuevamente a la del moro enamorado, ya que, sumido en la melancolía, el galán se interna en el bosque y se dedica a romper el aire con suspiros apasionados, también característicos de Abindarráez.

10 La prodigiosa de Juan Pérez de Montalbán, incluida en Sucesos y prodigios de amor (1625), resulta, tal vez, la novela de menor calidad del volumen y, quizás por eso, la que menos suscita el aliento crítico del lector. En tanto incorporada del modelo bizantino, plagado de aventuras y confusiones (de allí el empleo del término prodigio dentro del texto y el adjetivo derivado en el título), la novela cuenta con un enredo tan complicado que merece el siguiente aserto de Bonilla Cerezo: «Pérez de Montalbán postula y deroga a capricho las normas de la verosimilitud» (p. 73). En ese tránsito hacia la nada, cuando los cabos se atan solo hasta el final, diríase que se encuentra el reflejo deformado, casi monstruoso, de la fórmula de Lope, con quien Pérez de Montalbán se declaraba tan en deuda. En lo que se refiere a la anotación filológica, llama la atención que en uno de los poemas intercalados aparezca el personaje tradicional de Teresa, en su faceta pastoril (y no de joven urbana, fregona, como en Teresa de Manzanares, su obra cumbre), pero manteniendo su esencia de muchacha dada a las burlas, «pastora hermosa y mudable,/ y de condición traviesa» (p. 205)

11 La cuarta novela de la antología, Del celoso desengañado de Juan de Piña, es el texto más complejo y ambicioso, dentro del marco de expectativas del género, de toda la antología. «Una pieza de horror o de truculencias que no cristaliza como tal» (86), sostiene el editor. Nos inclinamos a pensar que quizás, plenamente consciente de sí misma, la novela muestra sus costuras adrede. En eso, está en el sendero de las Novelas a Marcia Leonarda, como bien lo advierte Bonilla, tanto como en el de El celoso extremeño y El curioso impertinente de Cervantes. Una muestra de la empatía con Lope se encuentra en el elogio que se hace del Fénix, inserto en una de las digresiones a las que es tan dado el narrador. A Bernardo, el celoso, le sigue el juego la astuta Teodora, quien echa mano de su conocimiento profundo del teatro. Así, el narrador llama a sus gestos teatrales «hijos legítimos de solo su divino ingenio y del arte amandi en las insignes comedias del que las sacó del caos de las ignorancias, chozas y oficinas a las luces eternas hasta el fin del mundo» (p. 251). Pues bien, aquel ars amandi no parece referirse tanto a la obra de Ovidio, como señala la nota del editor, sino que forma parte del homenaje a Lope de Vega. Existe un ars amandi en el universo lopesco, minuciosamente desarrollado en la correspondencia que el Fénix sostuvo con su señor, el Duque de Sessa ${ }^{11}$, y que se encuentra plasmado también, entre líneas, en su obra dramática.

Del celoso desengañado desarrolla el conflicto clásico de un triángulo de amantes, con la singularidad, digna de resaltar, de que los personajes elaboran sus enredos con plena consciencia de su dimensión parateatral. Bernardo es el celoso esencial, rico y sin mayores dificultades, mas inseguro de su esposa. Don Diego, en cambio, tildado como perteneciente al grupo de los «lindos» (p. 258), es un sujeto vanidoso y galante, el intruso al que le fascina este juego de tira y afloja con la dama Teodora. No obstante, lo 
más sorprendente del argumento, que debía complacer al lector, es la anagnórisis de don Diego como padre de Teodora. En el momento en que este acaba su relato, es la propia muchacha quien revela esta verdad y observa su carácter metaliterario: «Si tuviera celos don Bernardo del señor don Diego y de mí, con tan buen desengaño le pudiéramos llamar el celoso desengañado [nombre precisamente de la novela que estamos leyendo, y por ello creo que debería estar en cursivas] y si el cuento fuera novela venía a ser excelente el título» (p. 266). Teodora emplea dos términos con significados bien exactos: tradicionalmente se establecía la condición oral del «cuento» frente al registro escrito, y por ende mucho más artístico, al que se ceñía la novela ${ }^{12}$. En este momento de la trama, la novela es totalmente autoconsciente y la protagonista nos introduce, ya de lleno, en una dinámica metaficcional que trae consigo un cierto aroma cervantino.

Ingresando a los médanos de la anotación filológica, debería aclararse el significado de «transportín», que es "colchón pequeño y delgado», según el Diccionario de autoridades, una suerte de "sobre de dormir" de la época, por lo que hay que descartar la referencia al DRAE que se hace en la nota («lo mismo que trasero, asentaderas», se dice en nota a pie, p. 272) ${ }^{13}$. El significado que traemos a cuento ahora aclara más el pasaje, una extensa digresión en torno a la conducta noble, que se afirma debiera ser generalmente austera, por lo cual se refiere que el descanso habría de hacerse sobre un «transportín o almofrej», ya que deben dejarse «las almohadas para el sepulcro y las sábanas para la otra vida» (p. 272). Un poco más adelante, ya en términos de edición del texto, convendría separar el discurso del narrador de aquel del personaje (p. 277) y corregir el gazapo de «acotar» (p. 280), que evidencia la digitalización del texto (cuyo original debía leer «açotar»).

Otro pasaje filológicamente rico se encuentra en la charla entre Teodora y Bernardo, cuando esta hace el siguiente comentario sobre el encuentro de don Diego con doña Inés: «Y elegido para esta noche don Diego, no dirá, siendo de Sevilla, que es la toledana, matáranse a concetos sino a celos» (pp. 278-279). El editor observa, atinadamente, el juego de palabras con «la noche toledana», así como con las espadas de Toledo, pero además podríamos añadir el sentido de "discreta», dada la fama de serlo que poseían las mujeres toledanas ${ }^{14}$; se trataba de un lugar común que inclusive inspiró una comedia de Lope de Vega, La gallarda toledana. De allí que, de ser Inés toledana (que no lo es, ya que se ha dicho más arriba que es de Sevilla), la pareja se mataría «a concetos sino a celos». Páginas más adelante, ya en la conclusión de la obra, se reflexiona sobre la tortura y el dolor que suponen los celos para el honor masculino, a través de la referencia a la fragilidad del vidrio con que se equipara, tópicamente, el honor: "Que los celosos son incendios de su honor, y los que más fácilmente son engañados descubiertas sus imaginaciones. El vidro es quebradizo, esmalte que desampara el oro» (p. 282) $)^{15}$.

En quinto lugar, encontramos la novela El culto graduado de Alonso de Castillo Solórzano. Su autor era un defensor de Lope, respetuoso de Góngora, pero contrario a la innovación de su estilo y mucho más a sus necios seguidores en la corte. No escatimaríamos el adjetivo de "satírico» al relato que pergeña Castillo Solórzano, como lo hace el editor reservándose la opinión sobre el carácter satírico del texto (p. 95). Alcaraz, diríamos nosotros, es infame en la medida en que es ridículo, necio y pretencioso y el estilo «alto» se vuelve «bajo» gracias a la degradación a la que lo somete el autor exagerando los recursos que todos los detractores del culteranismo consideraban sus vicios. Y esta infamia o bajeza empieza por su nombre, si se nos está 
permitido especular: «Alcaraz» podría jugar ingeniosamente con "carajo" o "caraj", como conteniendo una imprecación ("al carajo"). Se trata de una hipótesis indemostrable, pero no por ello menos sugerente. Quizás vale la pena recordar, a este propósito, que la pionera edición de Tardes entretenidas a cargo de E. Cotarelo lee «el bachiller Alcázar» ${ }^{16} \mathrm{y}$ mantiene ese nombre consistentemente a lo largo del texto, tal vez porque entendiera la alusión obscena y la censurase.

El análisis de Bonilla Cerezo señala correctamente al personaje de Alcaraz como germen de los figurones, personaje esperpéntico que Castillo Solórzano acuñará en los años siguientes (en su pieza dramática El mayorazgo figura más específicamente). La anotación que se lleva a cabo sobre el texto editado es en general adecuada y pertinente. Solo quisiéramos explicar la alusión a Ginebra en una de las prerrogativas que se le otorgan al graduado culto: «Le damos facultad para escribir fábulas en los versos que más gustare, procurando en todo guardar las constituciones de la república de Ginebra, en que asisten varias naciones hablando diferentes lenguas» (p. 329). En el fragmento, además de llamar la atención sobre el vínculo entre el género de la fábula mitológica y el estilo culterano, se alude a la idea de confusión lingüística que connotaba la ciudad ginebrina, dadas las guerras religiosas que la habían asolado ${ }^{17}$. Asimismo, vale la pena resaltar la función de aquella fuerza de choque del tiempo carnavalesco que constituyen los muchachos que rodean al bachiller Alcaraz al escapar de la ceremonia de graduación culta (comparsa típica de los locos en las calles), así como el desenlace que vuelve a vincular al protagonista loco con don Quijote: Alcaraz, derrotado y enfermo en su pueblo, se encuentra al borde la muerte y solo entonces recupera su cordura y logra desterrar de su atención el estilo culterano.

Es notable la observación de Bonilla Cerezo, quien comenta la interacción entre prosa y emblemas que establece la estructura de la colección de Tardes entretenidas; sería necesario entonces aplicarla a los «enigmas» que se presentan después de la lectura de El culto graduado entre el público que ha escuchado la novela. Aquí los dos emblemas que se usan para las adivinanzas reflejan sendos motivos fundamentales en el texto: la puerta (el mismo Bonilla considera que hay un «laberinto de puertas» que encierra el espectáculo para unos pocos, burladores del bachiller, privilegiando el espacio privado, en detrimento del público, como un gesto reaccionario aristocrático) y el libro (que tantas desdichas, por su ignorancia, produce en el protagonista, cuya falta de letras es fatal). Así, se hace evidente que los «enigmas» juegan en pared con los diversos ejes temáticos que componen este volumen de novelas del novel Castillo Solórzano hacia la época de publicación de sus Tardes entretenidas.

18 Finalmente, una novela como El culto graduado, cuyo núcleo es una burla compleja que pretende ser aleccionadora, estimula los afanes de clasificación a los que se encuentra inclinada vocacionalmente la crítica. ¿No convendría hablar de «novela burlesca» para referirse a textos como este? La nómina de esta subespecie narrativa breve incluiría además una novela como El celoso hasta la muerte del mismo Castillo Solórzano (proveniente del volumen Noches de placer) o la de Tirso de Molina conocida modernamente bajo el nombre de Los tres maridos burlados, pieza incluida en Los cigarrales de Toledo, así como las numerosas que pergeñó Alonso Jerónimo de Salas Barbadillo, varias de las cuales integran el nunca bien ponderado Corrección de vicios (1615). El rótulo de novela «burlesca» o «jocosa» serviría para llamar la atención sobre sus puntos de contacto con el entremés y con el género de la comedia burlesca misma, parte de cuyo reclamo estrictamente humorístico adoptaría. 
La antología se cierra con El monstruo del Manzanares de Andrés Sanz del Castillo. Realmente, parece difícil agregar algo al elaborado y completo artículo que firmó Armando Pego en 1995, como si este agotase toda la novela ${ }^{18}$. No obstante, nos permitiremos elaborar algunas reflexiones a propósito de ciertos pasajes jugosos del texto. Así, en torno a la anotación filológica, se echa en falta explicar la expresión «despepitado ánimo» (p. 349), o sea un ánimo o ímpetu «determinado y colérico, que no tiene pituita, que es flema» ${ }^{19}$, para completar la descripción del susodicho monstruo en pleno ultraje sexual a su víctima. Algunas páginas después, consumado el estupro de la joven Flora y al iniciarse la búsqueda de su violador, encontramos un vocablo de significado algo oscuro: «Y saliéndose con el caviloso acompañamiento al aspurgatorio y busca de su, si no robada, engañada Olimpia...» (p. 357). Dado el contexto, no parece suficiente considerar que se trata de un simple derivado de 'purgatorio', según se sostiene en la nota respectiva. La palabra parece traer a cuento expurgatorio, como derivación de expurgar, «limpiar» o «eliminar», en este caso, el monstruo. Además, el término bebería de asperges, "voz puramente latina usada en estilo jocoso como substantivo masculino y vale lo mismo que rociadura o aspersión $»^{20}$, ya que, como se describe más adelante, se dispone que los alguaciles y corchetes «se esparciesen entre la espesura de los álamos y enmarañado de los parrales al descubrimiento del monstruo» (p. 357), al que precisamente quieren expurgar. El término no deja de sonar algo ridículo, pero es lo que caracterizaría a la afectación de este tipo de prosa narrativa.

De paso, sería necesario comentar la identificación de la joven Flora con una «si no robada, engañada Olimpia», personaje proveniente del Orlando furioso, quien fue seducida, raptada y abandonada después en una isla por Vireno; esta pareja de amantes pasó al romancero y tuvo gran fortuna en las letras auriseculares hasta volverse un lugar común. En el mismo sendero de alusiones a obras clásicas de su tiempo, que resaltan la dimensión metaliteraria de la pieza de Sanz del Castillo, conviene reparar en la alusión a Leucipe y Clitofonte, novela bizantina de Aquiles Tacio, romanceada por Diego de Ágreda y Vargas en 1617: se lamenta don Juan de no haber gozado a su amada Flora y ser «más dichoso el robador de Leucipe que el amador de Clitofonte» (p. 364). La nota a pie a página, robusta síntesis del género bizantino, se queda sin abordar el sentido literal del pasaje. La comparación que entraña la referencia a la pareja griega es donairosa: el amante se queja de que su constancia, propia de Clitofonte («el amador de Clitofonte», el amante que guarda la virtud de su amada), no valga nada frente al embate del «robador de Leucipe», o sea aquel amante sin escrúpulos que, apelando a artimañas, la posee y hace un «ramillete de flores» (p. 364) del jardín de la amada, o sea que se apropia de su virginidad, su «flor» o pureza.

21 En este mismo fragmento se menciona que Flora sería conducida al encuentro «con el menor ruido que pudiesen» (p. 364) y se alude, más adelante, a la figura de la lechuza como «madre de nocturnas aves» (p. 365), emblema, a su vez, del silencio. Estos detalles, sumados a la ausencia de diálogos que reproduzcan las voces de los personajes o la mínima presencia de discursos atribuibles a ellos nos deben llevar a considerar que el silencio configura un tema en sí mismo dentro de El monstruo de Manzanares y es un elemento constituyente del sentido final de la novela. Por ello, la comparación del prolongado mutismo en la pieza de Sanz del Castillo con un supuesto sentido cómico o al menos paródico de Las fortunas de Diana va descaminado: en la pieza lopesca no habría ironía, parodia o «burla de tópicos sentimentales» (p.114), sino un consejo de 
prudencia social, de origen político, que se transfiere a la experiencia femenina, cuyo modelo bebe de un perfil varonil ${ }^{21}$. Bajo esta perspectiva, en $\mathrm{El} \mathrm{monstruo} \mathrm{del} \mathrm{Manzanares}$ el mutismo operaría como una expresión del miedo al escándalo y el deshonor que acecha a los personajes, quienes han cedido sus intervenciones al monólogo de un letraherido narrador, con frases a veces infelices, pero pretenciosas y floridas: el coche es llamado «concha de su preciosa margarita» (p. 349), tal como se describe la violación como «talado virginio» (p. 360) o un «nevado embajador» (p. 356), por un mensajero anciano, o se menciona una «tachonada falúa» (p. 366), para referirse a un coche. Nos hallamos en el reino del eufemismo, del arte elusivo culto, cuyo carácter hermético llama la atención sobre su artificiosidad.

Podría inclusive especularse que el recurrente mutismo de los personajes así como las menciones al silencio se proponen crear un contraste, con propósito artístico, frente al estilo afectado, pretenciosamente sensual y sonoro, por así decirlo, en que está escrito el texto. Convendría recordar un artículo clásico de Alan Trueblood a este respecto, quien establecía dos tipos de silencio en los personajes auriseculares: el silencio positivo o elocuente, propio de lo inefable, empapado del bucolismo de aquel «maravilloso silencio» que rodea ciertas escenas cervantinas, por ejemplo; y un silencio más bien negativo, un 'tener que callar' propio de la cautela, la prudencia o incluso la timidez ${ }^{22}$. En El monstruo del Manzanares se observa el tránsito de un silencio con dobles intenciones (engaño, cautela, vergüenza, deshonra, pudor, etc.) hacia uno vinculado al encierro monacal, el que abraza un escarmentado don Juan al final de la obra.

Huelga agregar que, a partir de estos breves apuntes muy sueltos, se evidencia que un texto como El monstruo del Manzanares merece ser reconsiderado y analizado con una mayor atención crítica que la que ha merecido hasta ahora. Y lo mismo podría afirmarse sobre las otras novelas que, con tan buen tino, ha elegido Bonilla Cerezo para conformar su antología. Este sucinto examen nos lleva, entonces, a la conclusión de que Novelas cortas del siglo XVII provee a los especialistas en narrativa áurea y afines de un material de consulta y reflexión obligatorias en lo porvenir.

\section{NOTAS}

1. Desde el trabajo de E. Rodríguez Cuadros, Novela corta marginada del siglo XVII español. Formulación y sociología en José Camerino y Andrés de Prado, Valencia, Universidad de Valencia, 1979; hasta, con los matices y ajustes del caso, N. Romero-Díaz, Nueva nobleza, nueva novela: reescribiendo la cultura urbana del Barroco, Newark, Juan de la Cuesta, 2002; o el artículo seminal de G. Martínez Camino, «La novela corta del Barroco español y la formación de una subjetividad señorial», Bulletin of Hispanic Studies, 73, 1976, pp. 33-47.

2. R. Coll-Tellechea, Contra las normas. Las pícaras españolas (1605-1632), Madrid, Ediciones del Orto, 2005, pp. 18-19.

3. Sigue siendo útil a este respecto el artículo de Florence Yudin, «The Novela Corta as Comedia: Lope's Las fortunas de Diana», Bulletin of Hispanic Studies, 45, 1968, pp. 181-188. Otro análisis sugerente y más actual es el de A. Sánchez Jiménez, «Comedia y novela corta en El pícaro amante de José Camerino», Rilce. Revista de Filología Hispánica, 18, 2002, pp. 109-124. 
4. M. Morínigo, «El teatro como sustituto de la novela en el Siglo de Oro», Revista de la Universidad de Buenos Aires 2, 1957, pp. 41-61.

5. E. García Santo-Tomás, Espacio urbano y creación literaria en el Madrid de Felipe IV, MadridFranfkurt am Main, Iberoamericana-Vervuert, 2004.

6. M. Vitse, «Salas Barbadillo y Góngora: burla e ideario de la Castilla de Felipe III», Criticón, 11, 1980, pp.5-142. Este trabajo disecciona minuciosamente los procedimientos de la burla, su significado, propósitos y estética.

7. Basta con consultar la útil antología de E. Cano Turrón, Fábulas mitológicas burlescas del Siglo de Oro, Córdoba, Berenice, 2007.

8. F. Rodríguez Mansilla, «La desdicha por la honra y la batalla en torno a Góngora», Anuario Lope de Vega, 16, 2010, pp. 105-123.

9. Anónimo, Historia del Abencerraje y la hermosa Jarifa, ed. F. López Estrada, Madrid, Cátedra, 1992, p. 118.

10. Hemos seguido la evolución de este personaje del cuentecillo tradicional hacia la novela picaresca en F. Rodríguez Mansilla, «La niña de los embustes, entre Salas Barbadillo y Castillo Solórzano», Dicenda. Cuadernos de Filología Hispánica, 27, 2009), pp. 109-130.

11. M. Chouza-Calo, «Lope de Vega's Letters: A Commentary on Love and Sexuality Against the Backdrop of Post-Tridentine Spain», Hispania Felix, 1, 2010, pp. 67-78.

12. M. Frenk Alatorre, Entre la voz y el silencio (la lectura en tiempos de Cervantes), Alcalá de Henares, Centro de Estudios Cervantinos, 1997, pp. 65-66.

13. En el capítulo VIII de Teresa de Manzanares, un ermitaño provee a la heroína de «un transportín de hojas de enea y espadañas» para que pueda pasar la noche en el campo (A. de Castillo Solórzano, La niña de los embustes, Teresa de Manzanares, Barcelona, DeBolsillo, 2005, p. 136).

14. Así, en La ilustre fregona, M. de Cervantes observa: «Antes mirarás hermosas que bocas en esta ciudad [de Toledo], que tiene fama de tener las más discretas mujeres de España, y que andan a una su discreción con su hermosura» (Novelas ejemplares, ed. J. B. Avalle Arce, Madrid, Castalia, vol. 3, p. 73). La misma idea se presenta en La hija de Celestina de A. J. de Salas Barbadillo (Picaresca femenina, ed. A. Rey Hazas, Madrid, Plaza y Janés, 1986, pp. 137-138).

15. Compárese, ante la abundancia de ejemplos posibles, tan solo el lamento de Peribáñez: «iAy, honra, al cuidado ingrata!/ Si eres vidrio, al mejor vidrio/ cualquiera golpe le basta» (Lope de Vega, Peribáñez. Fuenteovejuna, ed. F. Pedraza Jiménez, Madrid, Edaf, 2003, vv. 2082-2085).

16. A. de Castillo Solórzano, Tardes entretenidas, ed. Emilio Cotarelo y Mori, Madrid, Biblioteca de Bibliófilos Españoles, 1908, p. 308; dado que el cambio de «Alcaraz» a «Alcázar» es sistemático en todo el texto, resultaría más que difícil atribuirlo a una errata.

17. F. Rodríguez Mansilla, «Un Quijote culterano: El culto graduado de Alonso de Castillo Solórzano», Bulletin of Hispanic Studies (en prensa).

18. A. Pego, «Un discurso jurídico y literario sobre el amor: El monstruo de Manzanares», Dicenda. Cuadernos de Filología Hispánica, 13, 1995, pp. 227-247.

19. S. de Covarrubias, Tesoro de la lengua castellana o española, ed. I. Arellano y R. Zafra, MadridFrankfurt am Main, Iberoamericana- Vervuert, 2006, s.v. despepitado.

20. Real Academia Española, Diccionario de Autoridades, ed. facsímil, Madrid, Gredos, 1990, vol 1, s.v. asperges.

21. F. Rodríguez Mansilla, «Las imágenes del sol y la luna en Las fortunas de Diana», Hispania Felix, 1, 2010, pp. 123-136.

22. A. S. Trueblood, «Nota adicional sobre Cervantes y el silencio», Nueva Revista de Filología Hispánica, 13, 1958, p. 100. 